\title{
Brake Squeal Analysis using Finite Element Analysis Method
}

\author{
Yatesh Patil ${ }^{*}$, Subim Khan ${ }^{\#}$, Shoaib Iqbal ${ }^{\$}$, Amol Bankar ${ }^{@}$ and Maheshwari Patil ${ }^{\#}$ \\ *,\#JSPM Rajarshi Sahu College of Engineering, Pune \\ \$,@ Tata Motors, Pune.
}

(Received 18 May 2020, accepted 28 September 2020)

https://doi.org/10.36224/ijes.130301

\begin{abstract}
The Finite Element Analysis (FEA) is widely used for solving many Engineering problems. This paper focuses on use of FEA for Brake Squeal Analysis. Automobiles generates several kinds of noises like Groan, chatter, judder, moan, and squeal. Brake squeal can be defined as an unwanted noise that occurs due to dynamic instability of the system. It generally occurs in the frequency range of $1 \mathrm{KHz}$ to $16 \mathrm{KHz}$. The aim of the project is to predict the squeal noise occurring at particular frequencies at an early stage of development using full corner brake model. The preprocessing of the full corner brake model is done using Hypermesh while the processing and post-processing is to be carried out by using Abaqus. Analysis uses non-linear static simulation which is followed by Complex Eigen Value (CEA) extraction for carrying out the squeal Simulation. It provides the relation between damping ratio and frequency (Real part of the complex Eigen value). If the damping ratio at any particular frequency is above one, it can be said that squeal will occur at that particular frequency.
\end{abstract}

Keywords: Abaqus, Brake squeal, Complex Eigen Value, Finite Element Analysis, and Hypermesh

\section{Introduction}

Use of numerical analysis tools to analyze the brake noise performance has become area of interest since computers have become capable of performing complicated simulations using Finite Element Analysis (FEA) techniques. This has resulted in a considerable improvement in designing brakes which perform better from the noise point of view.

Squeal noise is a problem that occurs in the disc brake of automobiles. This problem has been encountered as one of the major industry problem due to customer dissatisfaction. Brake squeal doesn't not impact much on the performance of Automobile but the annoying noise make end user unsatisfied and hence it is if great importance. Physically, Brake squeal occurs because of the friction coupling between the components of the brake system which creates dynamic instability. This causes the vibrations which radiates the noise in the frequency range of $1 \mathrm{KHz}$ to $16 \mathrm{KHz}$. The noise in this range is called as Squeal.

In the previous few decades, lot of research has been carried out by many researchers to try and eliminate brake squeal to improve the vehicle user's comfort and thus reducing the overall environmental noise. A good progresshas been achieved and a variety of solutions have been implemented like reduction of the impulsive excitation, use of additional damping shims and transfer of modal coupling. Even after these efforts, squeal still remains to occur repeatedly within audible frequency range. Therefore, this problem required detailed and in depth study for prediction and elimination of brake squeal. 
There are two types of disc brakes available in market, one is fixed caliper and other is floating caliper. The fixed caliper does not move when the brakes are applied. It consists of pistons on both sides of disc. When the brakes are applied, the pistons apply the brake pads on both sides against the rotor. Fig 1 shows the fixed caliper type disc brake.

PADS NOT APPLIED

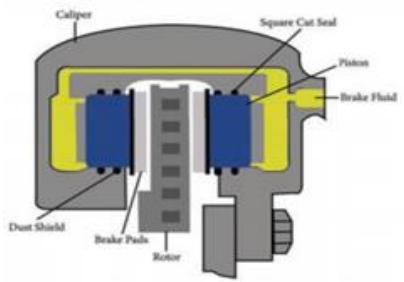

PADS APPLIED

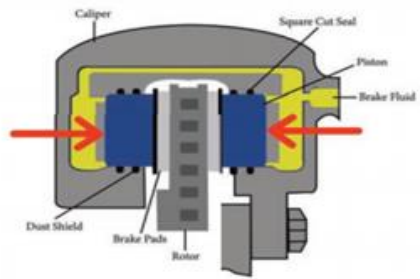

Figure 1: Fixed caliper

Floating caliper has pistons on only one side of the disc. When the brake pedal is applied, the piston comes out and applies on the inboard pad. At the same time, as the piston comes out, the caliper itself slides inward due to reaction force to apply the outboard pad. Fig 2 shows working of floating caliper. This project makes use of floating caliper.

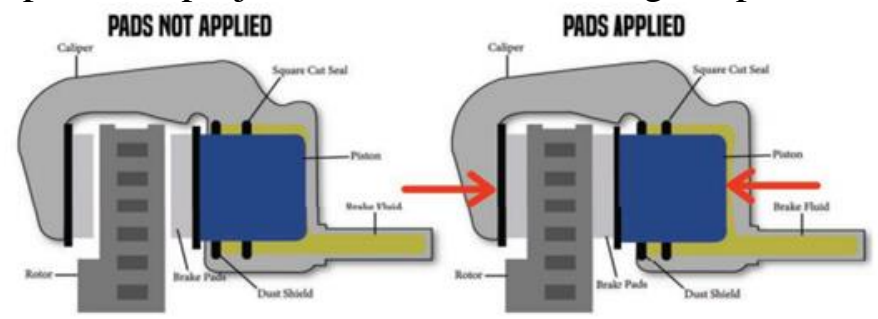

Figure 2: Floating caliper

There are two different methods which can be used to predict squeal using Finite Element Method (FEM), and those are Complex Eigenvalue Analysis (CEA) and Transient Dynamic Analysis (TDA). Both the methodologies have their own pros and cons. The CEA determines the complex eigenvalues by linearization of the equation of motion around equilibrium point. According to the basic stability theory, the positive real parts of the complex eigenvalues indicate the degree of instability of the linear model of a disc brake and are thought to show the likelihood of squeal occurrence. On the other hand TDA is able topredict real unstable frequencies that can be verified by experiments. The drawback of TDA is that it is very time consuming as well as it does not provide any information on unstable mode shapes. And hence this project uses Complex Eigenvalue Analysis to solve the squeal problem.

\section{Objectives}

Following are the objectives of this project

i. To identify the Brake squeal frequencies at an early stage of development

ii. To eliminate the squeal modes/frequencies and critical contributing components using complex Eigen value analysis.

iii. To find out Component Contribution Factor (CCF) and Component Mode Contribution Factor (CMCF) for full corner brake model

iv. To find the natural frequencies and mode shapes of Brake components in Free-Free condition 


\section{Literature review}

Huajiang Ouyang, Wayne Nack, Yongbin Yuan, Frank Chen [1] have covered two major methods generally used in the automotive industry, namely the complex eigenvalue analysis and the transient dynamic analysis. This review gives the analyst an Idea of choosing the correct methods. It is found from this paper that the complex eigenvalue analysis is still the method used by the automotive industry as compared to transient dynamic analysis approach.

A Söderberg, U Sellgren, S Andersson [2] presents an approach for simulating wear on both the contact surfaces of the pad and rotor interface in disc brake by making use of general finite element software. It presented two simulation cases. The first one addresses run in wear under constant load and response to application of brake at same constant brake load. The second case focuses on to observe the impact of change in lower load if the contact surfaces have been run in at a higher load level.

Abd Rahim Abu-Bakar, Huajiang Ouyang [3] presents a detailed Finite element model which considers the surface roughness of brake pads and allows the analysis into the contact pressure distribution which is affected by roughness and wear. The analysis results are well supported with the measured data. An newly developed numerical methodology consisting of three validation stages namely Modal analysis at component level, at assembly level and authentication of contact simulations. These two aspects have brought about significant improvement to the validation as well as analysis.

S. P. Jung, T. W. Park, J. H. Lee, W. H. Kim, and W. S Chung [4] represented a very simple Finite element model of a disc and two pads on either sides and CEA phenomenon was used to by rotating the disc at constant speed of $1400 \mathrm{rpm}$. The middle processor which uses the staggered approach was used to study the results of two other analysis domains: Mechanical and Thermal analysis. By interchanging the calculations results like contact power, heat distribution etc at every time step, solutions of thermo coupled system can be obtained. Pressure distribution of thepad surface was varied according to the direction of rotation of disc. Direct Temperature Variable and temperature of the disc were calculated and tendency was confirmed by earlier studies.

Q Cao1, M I Friswell, H Ouyang, J E Mottershead1 and S James [8] presents a paper consisting of numerical method for the computation of unstable natural frequencies of disc brake of a car. The disc was considered as a thin plate and all other disc components were modelled using finite elements software. Some of the unsure system specifications of the stable equipments and disc are tuned to fit experimental results. A linear, Complex-valued, asymmetric eigenvalue formulation is derived for disc brake squeal. Comparison of predicted unstable frequencies and experimentally determined squeal frequencies is well achieved.

M. Nouby, D. Mathivanan, K. Srinivasan [4] proposes an approach to study the important factors of the brake pad on disc brake squeal with statistical regression techniques. Complex eigenvalue analysis (CEA) is used as an finite element method to predict the unstable frequencies which causes squeal. The finite element results are compared with experimental results. Various factors act as an important influencer such as Young's Modulus of Back plate, number of slot, slot width etc. and they help to reduce the squeal using design of Experiment technique (DOE) method. 


\section{Methodology}

The full corner disc brake model consists of various parts which are modelled in design software and supplied to CAE team. The full corner model parts include Disc, Brake pad Inboard, Brake Pad Outboard, Caliper, Carrier, Backplate Inboard, Backplate outboard, Guide Pin, Pistons, Shims Inboard, Shims Outboard, Knuckle, Bearing, Hub, Tie rod, Strut, Ball joint, LCA Frame and LCA Bush. The full corner disc brake assembly is as shown in fig 3

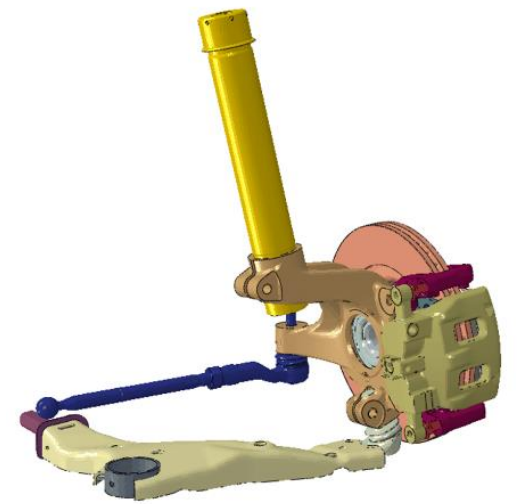

Figure 3: Full corner brake assembly

All these components are subjected to geometry clean-up before meshing in Hypermesh software. After meshing contact surfaces, Boundary conditions and constraints are applied in Abaqus software. Squeal investigation using the CAE approach is performed by running the FEA model by variation of pressure and variation of coefficient of friction. Different level of Pressure variation includes 5, 10, 20 and 30 bar while coefficient of friction variation includes 0.36 and 0.42 . The pressure is applied between piston and caliper. CAE approach gives the values of Natural frequency and damping ratio. Thus graph of Natural frequency V/S Damping ratio is plotted and if damping ratio at any frequency is greater than 1 , it indicates squeal at that particular frequency.

\section{Complex Eigen Value Analysis}

The Complex Eigen value Analysis (CEA) is used to determine the stability of the disc brake system. The method gives the solution in terms of real part and Imaginary part of the Eigen value and also damping ratio. In this analysis, the complex Eigen values using Abaqus are solved using the unsymmetrical method.

The Equation of motion of any vibrating system is:

$$
M \ddot{x}+C \dot{x}+K x=0
$$

Where, $\mathrm{M}=$ Mass Matrix

$\mathrm{C}=$ Damping Matrix

$\mathrm{K}=$ Stiffness Matrix

$\mathrm{x}=$ is the displacement vector.

For the stiffness matrix of friction induced vibrations has properties as:

$$
K=K_{\text {Structure }}+\mu K_{\text {Friction }}
$$

Where, $K_{\text {Structure }}=$ Structural stiffness matrix 
$K_{\text {Friction }}=$ Asymmetrical friction induced stiffness matrix $\mu=$ Coefficient of friction.

Both complex Eigen values and complex eigenvectors are generated by this unsymmetrical stiffness matrix. The governing equation can thus be rewritten as

$$
\left(\lambda^{2} M+\lambda C+K\right) \varphi=0
$$

Where,

$\lambda=$ Eigen value

$\varphi=$ Corresponding Eigenvector

$\mu=$ Coefficient of friction.

Complex Eigen value problem of the kind defined by above is solved by symmetrizing by ignoring the damping matrix $\mathrm{C}$, The asymmetric contributions to the stiffness matrix $\mathrm{K}$.Thus an imaginary number $\lambda=\mathrm{i} \omega$ is generated and the equation further becomes

$$
\left(\omega^{2} M+K_{\text {structure }}\right) \varphi=0
$$

Further projection subspace is used for solving the above problem. The $\operatorname{matrix}\left[\varphi_{1}, \varphi_{2}, \varphi_{3}, \ldots \ldots \ldots \varphi_{\mathrm{N}}\right]$ defines the format for expressing the $\mathrm{N}$ eigenvectors obtained from symmetric eigenvalue problem solution. Further the subspace of $\mathrm{N}$ eigenvectors is projected with the original matrices and is expressed as follows:

$$
\begin{aligned}
M^{*} & =\left[\varphi_{1}, \varphi_{2}, \varphi_{3}, \ldots \ldots \ldots \varphi_{1}\right]^{T} M\left[\varphi_{1}, \varphi_{2}, \varphi_{3}, \ldots \ldots \ldots \varphi_{1}\right], \\
C^{*} & =\left[\varphi_{1}, \varphi_{2}, \varphi_{3}, \ldots \ldots \ldots \varphi_{1}\right]^{T} C\left[\varphi_{1}, \varphi_{2}, \varphi_{3}, \ldots \ldots \ldots \varphi_{1}\right], \\
K^{*} & =\left[\varphi_{1}, \varphi_{2}, \varphi_{3}, \ldots \ldots \ldots \varphi_{1}\right]^{T} K\left[\varphi_{1}, \varphi_{2}, \varphi_{3}, \ldots \ldots \ldots \varphi_{1}\right],
\end{aligned}
$$

Complex Eigen problem thus projected becomes:

$$
\left(\lambda^{2} M^{*}+\lambda C^{*}+K^{*}\right) \varphi^{*}=0
$$

This equation is then solved using Eigen value problem solver. The original system eigenvectors are

$$
\varphi^{k}=\left[\varphi_{1}, \varphi_{2}, \varphi_{3}, \ldots \ldots \ldots \varphi_{\mathrm{N}}\right] \varphi^{* k}
$$

Where, $\varphi^{k}=$ approximation of the $k^{\text {th }}$ eigenvector of the previous (original) system. The eigenvalue pair for a specific mode is:

$$
\lambda_{i 1,2}=\alpha_{i} \pm \omega_{i}
$$

Where,

$\alpha_{i}=i^{\text {th }}$ mode real part

$\omega_{i}=i^{\text {th }}$ mode imaginary part

The complex conjugate Eigen value and eigenvector describes the motion for each mode:

$$
\left\{x_{i}\right\}=\left\{A_{i}\right\} e^{\left(\alpha_{i}+\omega_{i}\right) t}+\left\{A_{i}\right\} e^{\left(\alpha_{i}-\omega_{i}\right) t}
$$

Exponential cosine identity defines it as:

$$
\cos \omega_{i} t=\frac{\left(e^{j \omega_{i} t}+e^{-j \omega_{i} t}\right)}{2}
$$

The displacement can be rewritten as a damped sinusoidal wave:

$$
\left\{x_{i}\right\}=\left\{A_{i}\right\} e^{\alpha_{i} t} \cos \omega_{i} t
$$

Thus,

$$
x=A e^{\mu t}=\alpha+i \omega, x=e^{\alpha t}\left(A_{1} \cos \omega t+A_{1} \sin \omega t\right)
$$

$\alpha>0$, it implies unstable mode.

The mode of the complex pair with the positive real component is unstable and is an indicator of brake squeal. 


$$
\text { Damping ratio }=\frac{-2 \times \alpha}{\omega}
$$

Thus the negative damping ratio indicates an instability and hence damping ratio should be positive and should be less than 1 to indicate stability of the brake system.

\section{FE Modal Analysis}

The natural frequencies and corresponding mode shapes of the model are extracted by doing the modal analysis of the disc brake assembly. It indicates maximum (anti-node) and minimum (node) amplitudes in the form of displacement contour as shown in fig 4. The response frequency diagram, shows node and anti-node as a form of peak and anti-peak.

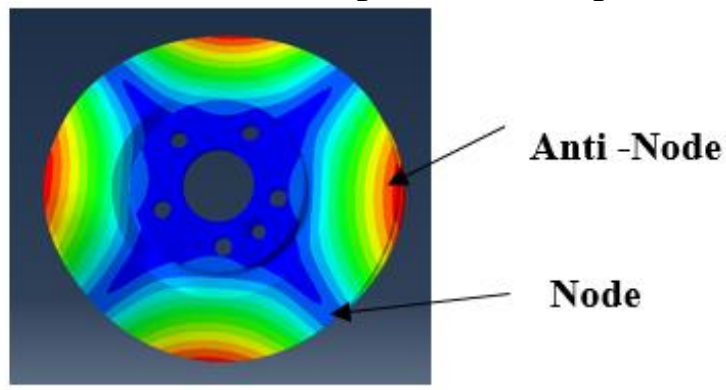

Figure 4: Vibration mode of disc

The FE modal analysis of some of the components of brake assembly is given below

\subsection{Disc}

The brake disc is one of the main reason for propagation of squeal and thus is important to study modal analysis of disc. Literature review reveals the relation between in plane and out plane modes of the disc as the primary reason for propagation of squeal. Disc is modelled by using Hexa elements. Some of the FE mode shapes of the disc at various frequencies are given below

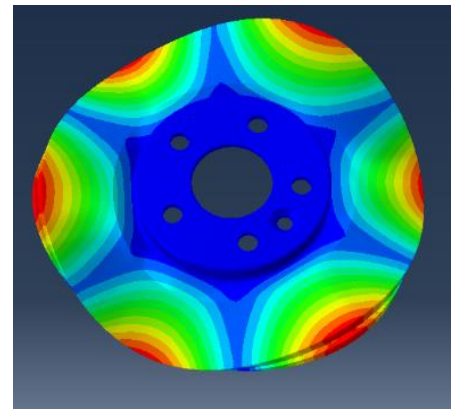

Figure 5: Mode shape at $2151.9 \mathrm{~Hz}$

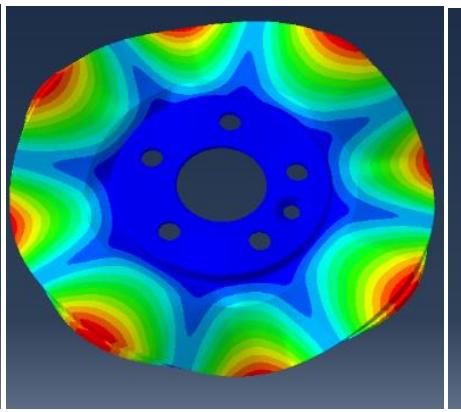

Mode shape at $3611.5 \mathrm{~Hz}$

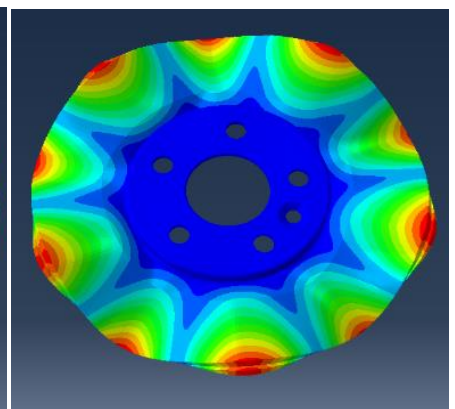

Mode shape at $5157 \mathrm{~Hz}$

\subsection{Brake Pads}

Brake Pad is a one of the important component in the squeal prediction. Due to the anisotropic nature of the brake pad there are lot of uncertainties associated in order to obtain exact properties of pad. The focus of this study is not to address these challenges, as most of the literature so far have assumed isotropic properties for the pad, this study have included these properties as anisotropic. For a better modelling of contact between brake disc and pad, friction pad is also 
modelled with Hexa elements. Some of the FE mode shapes of the brake pad at various frequencies are given below.
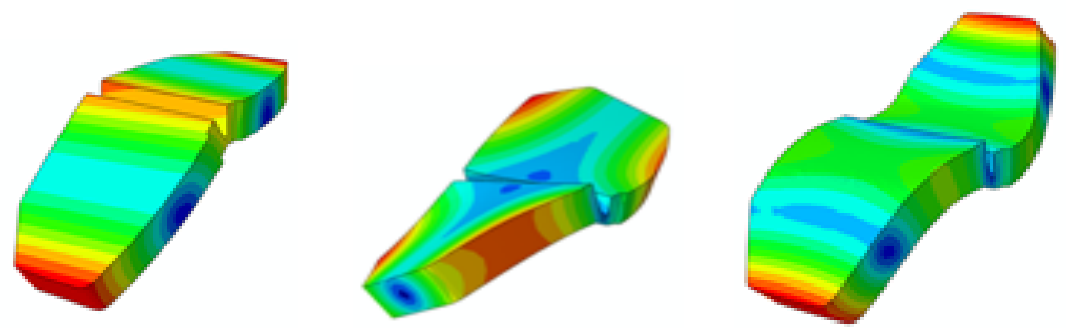

Figure 6: Mode shape at $1290.2 \mathrm{~Hz}$, Mode shape at $2593 \mathrm{~Hz}$ and Mode shape at $4642.4 \mathrm{~Hz}$, respectively

\subsection{Carrier}

Carrier is also as important as caliper housing and thus is considered for squeal predictions. The involvement of carrier in the squeal is due to the contact between the carrier with brake pad rear surface .The carrier also have a pivotal role in the working of the floating caliper disc working, since it is where the guide pins connects with caliper assembly, thus enabling the transfer of load to the other side friction pad. Some of the FE mode shapes of the brake pad at various frequencies are given below.

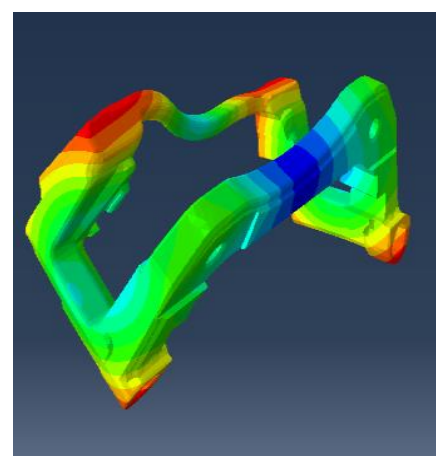

Figure 7: Mode shape at $1056 \mathrm{~Hz}$

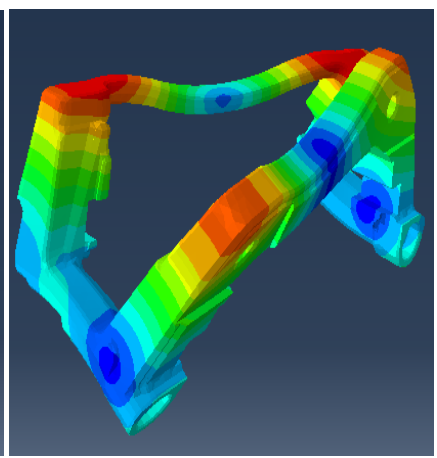

Mode shape at $1580 \mathrm{~Hz}$

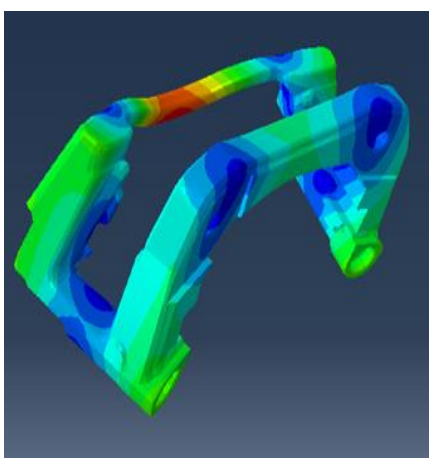

Mode shape at $1694 \mathrm{~Hz}$

\section{Results and discussion}

For authentication of squeal at various operating pressure and $\mathrm{COF}$ values, 8 series of simulations were carried out with various combination of pressure and coefficient of friction values.

The Four levels of pressure considered are:

i. $\quad 05$ Bars - It is for a very light brake pressure in typical usage

ii. $\quad 10$ Bars - It is for a moderate brake pressure

iii. $\quad 20$ Bars - It is for pressure during above average braking than usual

iv. $\quad 30$ Bars - It is for pressure during heavy braking condition

The results of the above pressure load cases are shown in the figure below 


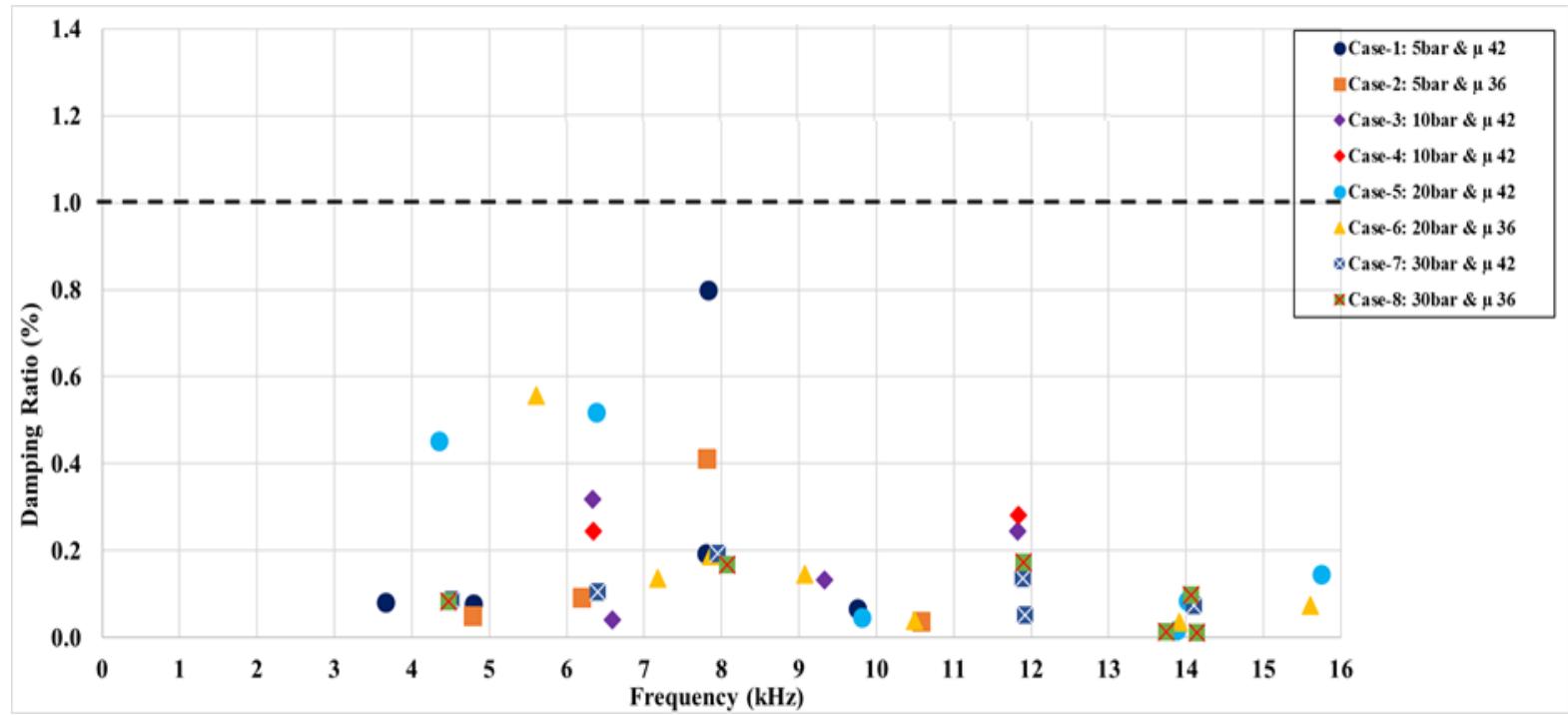

Figure 8: Results for brake system

The unstable modes are those modes which have damping ratio more than $1 \%$.It can be seen that none of the squeal frequencies show damping ratio more than $1 \%$. Hence it is concluded that no squeal occurs in current brake system.

\section{Component Contribution Factor (CCF) And Component Mode Contribution Factor (CMCF)}

Though there is no squeal in current brake corner module but in case if it occurs, CCF gives an idea of which component contributes the most in squeal phenomenon while CMCF gives an idea of which mode of that particular component contributes the most for causing squeal. The CCF and $\mathrm{CMCF}$ figures for one of the frequency is given below

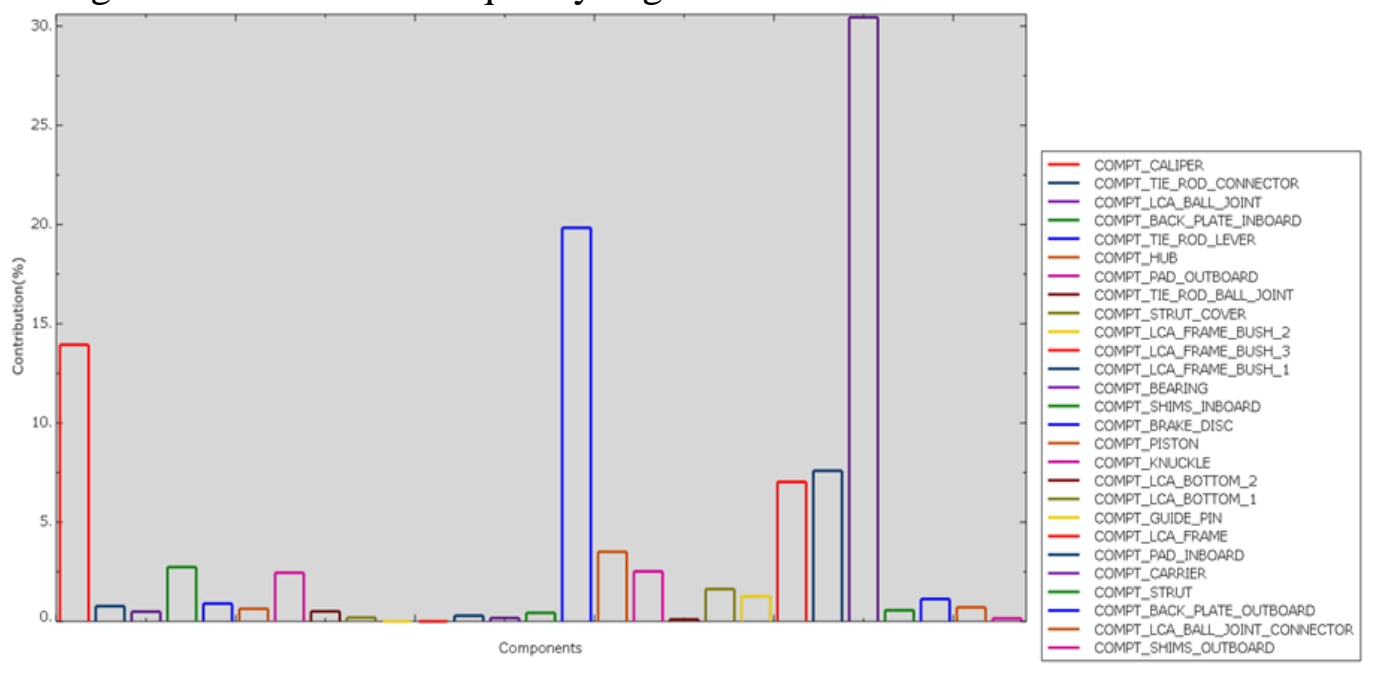

Figure 9: CCF plot at $2.6 \mathrm{KHz}$

Above Fig 9 shows the CCF plot at $2.6 \mathrm{KHz}$ and it can be observed that Carrier contributes the most for causing squeal. 


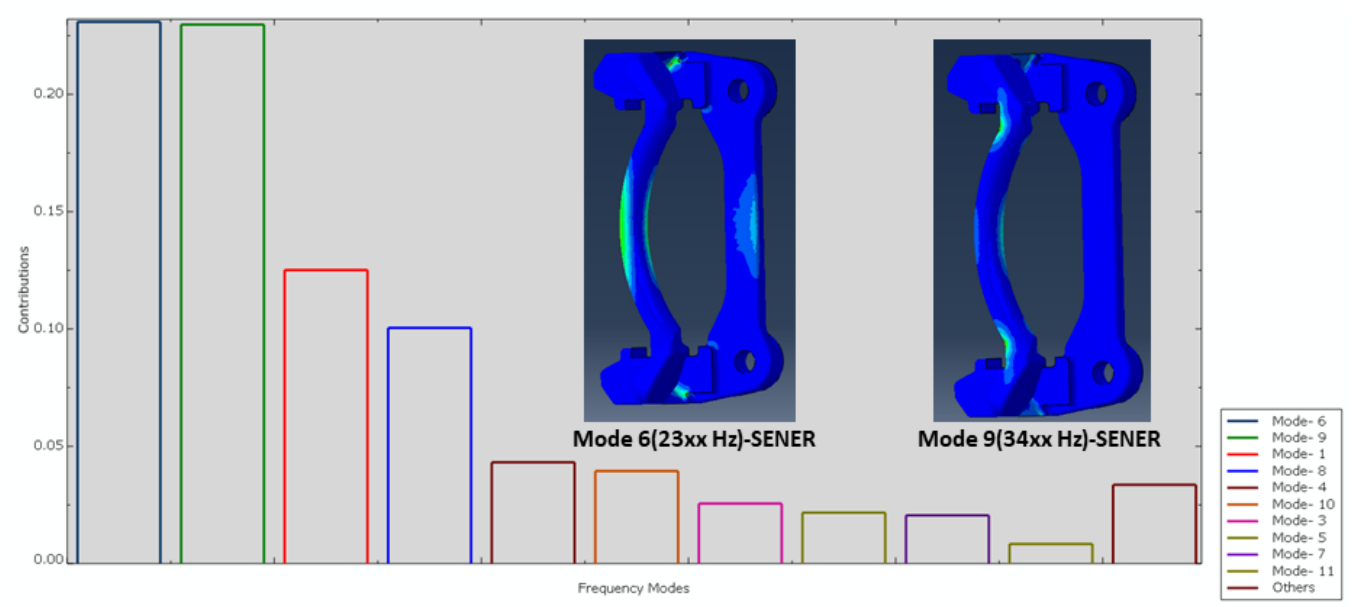

Figure 10: CMCF plot at $2.6 \mathrm{KHz}$

Figure 10 shows CMCF plot for the same frequency which was used to calculate CCF i.e. 2.6 $\mathrm{KHz}$ and it can be seen that Mode 6 of the carrier contributes the most for causing squeal.

\section{Brake Squeal Reduction Strategy in case it occurs}

Out of the different methods such as Material Modification such as variation of young's modulus of the material, Structural Modifications, Design of Experiments etc. which can be used to reduce brake squeal, Structural Modification method is preferred in most of the literature review. Structural Modification is nothing but change in geometrical shape of the components. In this case, structural modification was done on Brake pads as the squeal phenomenon is propended mainly from the contact surfaces of disc and pad, though other components which are interacting with pad such as caliper or carrier also could be responsible. This can be attributed to the load transfer through the pad interface. The major factor which is varied is the distribution of contact pressure due to change in contact area. The brake pad is provided with chamfers on both leading and trailing sides of the pad. The main of the chamfer is to transfer the center of contact pressure from the end edges of the pad close to center location so that the pad can make symmetrical fluttering during resonant motion and eventually reduce squeal.

The various configurations modelled for brake pad are as given in below figures

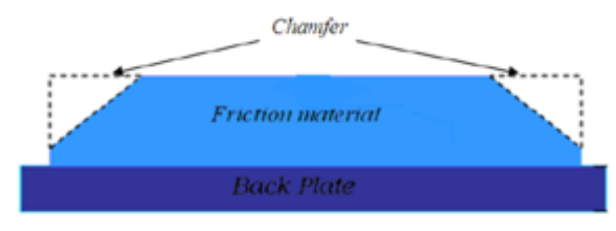

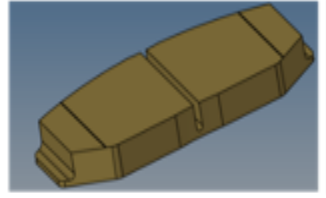

Figure 11: J chamfer pad

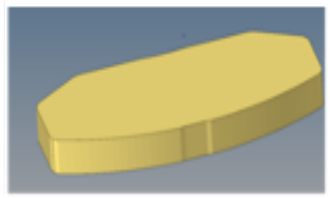

Figure 12: without slot

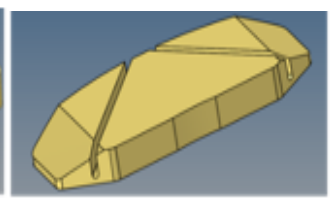

Figure 13: Lamda Slot

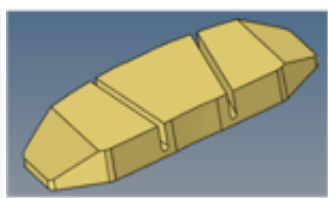

Figure 14: Radial Slot 
Of the various configurations modelled, Literature review revealed $\mathbf{J}$ chamfer showed most effective squeal reduction with less than $1 \%$ squeal index in almost all modes.

\section{Conclusion}

i. There was no brake squeal frequency observed in our disc brake system as the damping ratio at all the frequencies was less than $1 \%$.

ii. $\mathrm{CCF}$ helps to find the most contributing component in squeal phenomenon and $\mathrm{CMCF}$ helps to find out most contributing mode of that component for particular frequency.

iii. Various methods which can be used to avoid brake squeal such as material modifications, structural modifications, adding of shims and making slot and chamfer modifications are suggested.

\section{References}

[1] Huajiang Ouyang, Wayne Nack, Yongbin Yuan, Frank Chen, Automotive disc brake squeal simulation by Numerical method, Int. J. Vehicle Noise and Vibration, Vol. 1, Nos. 3/4, 2005

[2] A Söderberg, U Sellgren, S Andersson, To predict the brake pressure needed for cleaning of rotors by using finite element analysis 2008-01-2565

[3] Abd Rahim Abu-Bakar, Huajiang Ouyang, Recent Studies of Car Disc Brake Squeal, In: New Research on Acoustics ISBN 978-1-60456-403-7, pp.159-198 (C) 2008 Nova Science Publishers, Inc

[4] S. P. Jung, T. W. Park, J. H. Lee, W. H. Kim, and W. S Chung, Thermal elastic Instability of Disc Brakes by using Finite Element Analysis, Proceedings of the World Congress on Engineering 2010 Vol II WCE 2010, June 30 - July 2, 2010, London, U.K

[5] Q Cao1, M I Friswell, H Ouyang, J E Mottershead1 and S James, Study of the Theoretical and Experimental Material Science for Car Disc Brake Squeal forum Vols. 440-441 (2003) pp.269-276 (C) (2003) Trans Tech Publications, Switzerland.

[6] M. Nouby, D. Mathivanan, K. Srinivasan, To study the disc brake squeal by using combined approach of complex eigenvalue analysis and design of Experiment (DOE). International Journal of Engineering, Science and Technology Vol. 1, No. 1, 2009, pp. 254-271

[7] Hao Xing, Squeal Analysis of Disc Brake System, Beijing FEA online Engineering Co., Ltd. Beijing, China, 4th ANSA \& BETA International Conference.

[8] Rajendra Pohane, R. G. Choudhari, Design and Finite Element Analysis of Disc Brake, International J. of Engg. Research \& Indu. Appls (IJERIA). ISSN 0974-1518, Vol.4, No. I (February2011), pp 147-158.

[9] A. R. Abu-Bakr and H. Ouyang, prediction of the squeal of the Disc Brake by Complex eigenvalue analysis and Transient dynamic analysis ,Int. J. Vehicle Noise and Vibration, Vol. 2, No. 2, 2006.

[10] P. Liu a, H. Zheng a, C. Cai a, Y.Y. Wang a, C.Lu a,K.H. Ang b, G.R. Liu, Application of Complex Eigenvalue Method for carrying out disc brake squeal analysis, ScienceDirect, Applied Acoustics 68 (2007) 603-615. 